This item was submitted to Loughborough's Research Repository by the author.

Items in Figshare are protected by copyright, with all rights reserved, unless otherwise indicated.

\title{
Electrochemical impedance study on estimating the mass transport resistance in the polymer electrolyte fuel cell cathode catalyst layer
}

PLEASE CITE THE PUBLISHED VERSION

http://dx.doi.org/10.1016/j.jelechem.2013.05.008

\section{PUBLISHER}

(c) Elsevier

VERSION

AM (Accepted Manuscript)

\section{PUBLISHER STATEMENT}

This work is made available according to the conditions of the Creative Commons Attribution-NonCommercialNoDerivatives 4.0 International (CC BY-NC-ND 4.0) licence. Full details of this licence are available at: https://creativecommons.org/licenses/by-nc-nd/4.0/

\section{LICENCE}

CC BY-NC-ND 4.0

\section{REPOSITORY RECORD}

Cruz-Manzo, Samuel, and Rui Chen. 2014. "Electrochemical Impedance Study on Estimating the Mass Transport Resistance in the Polymer Electrolyte Fuel Cell Cathode Catalyst Layer". figshare. https://hdl.handle.net/2134/15612. 


\title{
Electrochemical Impedance Study on Estimating the Mass Transport Resistance in the Polymer Electrolyte Fuel Cell Cathode Catalyst Layer.
}

\author{
Samuel Cruz-Manzo and Rui Chen
}

Department of Aeronautical and Automotive Engineering, Loughborough University, LE11 3TU, UK

\begin{abstract}
In this study the mass transport resistance in the cathode catalyst layer (CCL) of a polymer electrolyte fuel cell (PEFC) is estimated using electrochemical impedance spectroscopy (EIS) measurements. Experimental impedance measurements for a $6 \mathrm{~cm}^{2}$ PEFC operated with two different relative humidity (RH) values in the cathode and different partial pressure of oxygen in $\mathrm{He} / \mathrm{O}_{2}$ and $\mathrm{N}_{2} / \mathrm{O}_{2}$ gas mixture were carried out. A mathematical model predicting the CCL impedance response, derived in the authors' previous study, is applied to EIS measurements to calculate the CCL mass transport resistance. The experimental results show the presence of an overlapped second semicircle at low frequencies which is attributed to an increase in the time constant to diffuse oxygen through the CCL when the PEFC is operated at low oxygen partial pressure, $\mathrm{p}\left(\mathrm{O}_{2}\right) \leq 20 \%$, in $\mathrm{He} / \mathrm{O}_{2}$ or $\mathrm{N}_{2} / \mathrm{O}_{2}$ gas mixture. The results also show that oxygen diluted with nitrogen can reduce the steady state oxygen concentration in the CCL-gas diffusion layer (GDL) interface and can increase CCL mass transport resistance. It is possible, as such, to harness capabilities from both modelling and real-world EIS data in a complementary manner.
\end{abstract}

Keywords: PEFC, EIS, mass transport resistance, cathode catalyst layer, impedance model 


\section{Introduction}

Polymer Electrolyte Fuel Cells (PEFCs) are the best candidates to be considered as the future source of propulsion for automobiles because they are able to produce high power density at low temperature and are not bound by the Carnot cycle. A PEFC converts the chemical energy of a fuel such as hydrogen gas into electrical energy. The study of mass transport resistance in the PEFC is of crucial interest, because the electrochemical reaction during hydrogen oxidation and oxygen reduction (redox) is affected by concentration gradients in the reactants supplied across the gas diffusion layer (GDL) and catalyst layer (CL), for example. GDLs and CLs contain a tortuous pore network for the supply and removal of reactant gases and product water, respectively. External gas humidification is desirable to ensure an appropriate humidification of the ionomer in the CL and the polymer electrolyte membrane (PEM). A high relative humidity (RH) enhances the ionic conductivity in the PEM and improves catalyst utilization and overall performance. Nevertheless, a high RH can result in pore saturation in the GDL and CL which will impede reactant transport. Electrochemical Impedance Spectroscopy (EIS) is an experimental technique that can be applied in-situ to separate the physical processes in the PEFC that occur at different rates through a frequency response plot. One of the challenges in EIS research is to quantify the mass transport limitations between the CCL and the GDL. The Randles circuit [1] has been broadly used in impedance plots to estimate mass transport limitations in PEFC EIS measurements. However, it has not been clear how to define whether this effect of oxygen transport limitation is dominated by the CCL or the GDL. In the authors' previous study [2], a mathematical model based on electrochemistry theory was developed to simulate the impedance spectrum of the cathodic side of a PEFC. The objective of the current study is to estimate the mass transport resistance in the cathode catalyst layer (CCL) using EIS measurements and the mathematical model developed in a previous study. To validate this work, experimental impedance measurements for a $6 \mathrm{~cm}^{2}$ PEFC operated with two different relative humidity (RH) values in the cathode and different partial pressure of oxygen in $\mathrm{He} / \mathrm{O}_{2}$ and $\mathrm{N}_{2} / \mathrm{O}_{2}$ gas mixture were considered. It is possible as such to harness capabilities from both modelling and EIS in a complementary manner. 


\section{Experimental}

A $6 \mathrm{~cm}^{2}$ PEFC was operated at $500 \mathrm{mAcm}^{2}, 80{ }^{\circ} \mathrm{C}, 20$ psig anode and cathode inlet pressures, $100 \%$ RH for the anode and 100/30 \% RH for the cathode. The flow rates were kept constant throughout the experiment at $125.5 \mathrm{sccm}$ on the anode and $313 \mathrm{sccm}$ on the cathode. The cell was allowed to sit at the required current on pure oxygen for 5 minutes and then the AC responses were measured. The gas was then switched to $80 \% \mathrm{O}_{2}$ in helium, held for a few minutes and then switched to $80 \% \mathrm{O}_{2}$ in nitrogen. The concentrations were then stepped down to $60,40,20$, and $10 \% \mathrm{O}_{2}$ in helium followed by nitrogen with impedance measurements taken at each point. The MEA was a developmental sample from Johnson Matthey Fuel Cells with $0.4 \mathrm{mg} \mathrm{Pt} / \mathrm{cm}^{2}$ on both anode and cathode. The thickness of the CLs was $10 \mu \mathrm{m}$. The membrane was a commercial $30 \mu \mathrm{m}$ perfluorinated sulphonic acid membrane. The gas diffusion layers were based on wetproofed Toray TGP-H-060.

How were the flow rates controlled?

\section{Model description}

In the authors' previous study [2], a mathematical model was developed based on fundamental electrochemical and diffusion theory to simulate the impedance spectrum of the cathodic side of a PEFC operated for any zone of the polarisation curve, as such:

$Z_{P E F C}=L_{H}(i \omega)+R_{e}+\frac{\left[R_{C}+Z_{W}\right] \gamma_{1} \operatorname{coth}\left(\gamma_{1} x\right)}{1+Y(i \omega)^{P}\left[R_{C}+Z_{W}\right]}$

With $\gamma_{1}=\sqrt{R_{p}\left[\frac{1}{R_{C}+Z_{W}}+Y(i \omega)^{p}\right]}$

$R_{P}$ is the resistance to the flow of ions in the electrolytic phase of the CCL; $R_{C}$ represents the charge transfer resistance during the oxygen reduction reaction (ORR) and is defined as $R_{C}=b / j_{0} \exp \left(\eta_{s \mathrm{~S}} / b\right)$, where $b$ is the Tafel slope, $\eta_{s s}$ represents the activation overpotential, and $j_{0}$ is the exchange current; $Z_{W}=R_{W} \tanh \left(i \omega T_{W}\right)^{0.5} /\left(i \omega T_{W}\right)^{0.5}$ is defined as the Warburg impedance and describes diffusion across a finite dimension in the frequency domain, with $R_{W}=R T \delta /\left(\mathrm{z}^{2} F^{2} c_{0}^{*} D\right)$ defined as resistance for the 
diffusion process and $T_{W}=\delta^{2} / D$ defined as the time constant to diffuse oxygen through the CCL; $Y$ represents a parameter related to capacitance, superscript $P$ represents a parameter to correct the inhomogeneity in the distribution of charge between the electrode-electrolyte inteface; $\omega$ is the angular frequency; $i$ is the imaginary component in impedance; $L_{H}$ represents the inductance in the electrical cables in the measurement system; and Re represents the total ohmic resistance to flow electrons and ions in the bipolar plate, GDL and PEM. In the authors' previous study [3] a reference electrode inserted in a PEFC operated with 100\% RH in the anode and a multichannel frequency response analyser allowed the separation of the impedance response of the cell and cathode. The results showed that anode mechanisms (hydrogen oxidation reaction) have not contribution in EIS measurements at low frequencies where oxygen transport limitations are commonly manifested $[3,4]$. Springer et al. [5] reported that there is a negligible difference in impedance response when measuring the cathode impedance relative to the anode or relative to a reference electrode place on the side of the anode. The anode contribution, neglecting any contaminant within the hydrogen supplied such as CO which affects the PEFC performance [6], can be considered negligible in these EIS measurements. Therefore Eq. 1 will be used to estimate the mass transport resistance in the CCL. The use of Eq. 1 with EIS measurements have already been demonstrated in previous studies [2,3,4]. The modelling predictions of Eq.1 can be compared with the experimental impedance curves for a PEFC operated with different partial pressure of oxygen in $\mathrm{He} / \mathrm{O}_{2}$ and $\mathrm{N}_{2} / \mathrm{O}_{2}$ gas mixture and two $\mathrm{RH}$ (100 $\%, 30 \%)$ in the cathode. The simulated data from Eq. 1 were compared with the measured EIS data using a Graphic User Interface (GUI) developed in Matlab®). The use of the GUI with Eq. 1 for EIS analysis has already been demonstrated in the authors' previous study [2]. The parameters of Eq. 1 were manually adjusted with experimental EIS measurements using the GUI to achieve a good agreement between the experimental and simulated data. In Eq. 1 there are some parameters that can also be estimated through a graphical interpretation of the Nyquist plot, as reported in a previous study [3]. This allows the reduction of the number of parameters to be fitted in the measured EIS spectra. The least-squares fitting method was used in order to find the best fit between the model and the measured data. 


\section{Results and Discussion}

The aim of this section is to estimate the mass transport resistance in the CCL when using $\mathrm{O}_{2}$ diluted in He and $\mathrm{N}_{2}$. For partial pressure of oxygen $\mathrm{p}\left(\mathrm{O}_{2}\right)>20 \%$ in $\mathrm{He} / \mathrm{O}_{2}$ or $\mathrm{N}_{2} / \mathrm{O}_{2}$ gas mixture, the kinetic and diffusion processes masked one another in the impedance plot. In EIS measurements carried out with $\mathrm{p}\left(\mathrm{O}_{2}\right) \leq 20 \%$ in $\mathrm{He} / \mathrm{O}_{2}$ or $\mathrm{N}_{2} / \mathrm{O}_{2}$ gas mixture an overlapped second semicircle at low frequencies which can be attributed to oxygen diffusion effect was apparent, as shown in Fig. 1. In this study only EIS measurements with $\mathrm{p}\left(\mathrm{O}_{2}\right) \leq 20 \%$ in $\mathrm{He} / \mathrm{O}_{2}$ or $\mathrm{N}_{2} / \mathrm{O}_{2}$ gas mixture were considered, as shown in Fig. 1, as it was possible to quantify accurately the charge transfer and mass transport resistances using Eq. 1.

\subsection{Diffusion Time Constant}

The presence of the overlapped semicircle at low frequencies is attributed to an increase in the time constant $T_{W}=\delta^{2} / D$ to diffuse oxygen through the CCL [3]. The diffusion time constant is related to the three principal modes of transport of $\mathrm{O}_{2}$ in the CCL: gas-phase diffusion in the CCL pore, diffusion in the liquid-water film surrounding a catalytic agglomerate, and diffusion in the ionomer of the agglomerate. The diffusion time constant for EIS measurements at $\mathrm{p}\left(\mathrm{O}_{2}\right)>20 \%$ in $\mathrm{He} / \mathrm{O}_{2}$ or $\mathrm{N}_{2} / \mathrm{O}_{2}$ gas mixture and $100 \%$ and $30 \% \mathrm{RH}$ and calculated through Eq. 1 resulted in 0.003 s. For EIS measurements carried out at $\mathrm{p}\left(\mathrm{O}_{2}\right) \leq 20 \%$ in $\mathrm{He} / \mathrm{O}_{2}$ or $\mathrm{N}_{2} / \mathrm{O}_{2}$ gas mixture an average value was calculated for $100 \%$ and $30 \%$ RH conditions. The average diffusion time constants for $100 \%$ and 30 \% RH were $0.08 \mathrm{~s}$ and $0.14 \mathrm{~s}$ respectively. Springer et al. [5] concluded that it is not possible to visualize the charge transfer and mass transport effects in PEFC EIS measurements with time constants of $10^{-4}$ and $10^{-3}$ orders of magnitude, and with either air or oxygen as a gas reactant. The finite diffusion distance $\delta$ for oxygen to reach the reaction sites in the CCL forms a complicated network of multi-phase parallel and serial paths and change in dimension for different CCL composition (e.g. nafion loading, porosity, tortuosity) and at different fuel cell operating conditions (current density, temperature, relative humidity, etc.) [7]. Assuming that the finite diffusion distance is the thickness of the CCL to simplify the analysis, the effective diffusion coefficient $D$ for EIS 
measurements at $\mathrm{p}\left(\mathrm{O}_{2}\right)>20 \%$ in $\mathrm{He} / \mathrm{O}_{2}$ or $\mathrm{N}_{2} / \mathrm{O}_{2}$ gas mixture at $100 \%$ and $30 \% \mathrm{RH}$ was calculated to be $3.33 \times 10^{-8} \mathrm{~m}^{2} / \mathrm{s}$. For $\mathrm{p}\left(\mathrm{O}_{2}\right) \leq 20 \%$ in $\mathrm{He} / \mathrm{O}_{2}$ or $\mathrm{N}_{2} / \mathrm{O}_{2}$ gas mixture at $100 \% \mathrm{RH}$ the effective diffusion coefficient was calculated to be $1.25 \times 10^{-9} \mathrm{~m}^{2} / \mathrm{s}$ and at $30 \% \mathrm{RH}$ was $7.143 \times 10^{-10} \mathrm{~m}^{2} / \mathrm{s}$. These values present the same order of magnitude as the diffusion coefficients for diffusivity of oxygen in gas phase $2.68 \times 10^{-8} \mathrm{~m}^{2} / \mathrm{s}$, liquid-water phase $2.00 \times 10^{-9} \mathrm{~m}^{2} / \mathrm{s}$ and ionomer phase $2.83 \times 10^{-10} \mathrm{~m}^{2} / \mathrm{s}$ as reported by Malevich et al. [1]. It can be concluded that the main contribution to oxygen transport in the CCL for $\mathrm{p}\left(\mathrm{O}_{2}\right)>20 \%$ in $\mathrm{He} / \mathrm{O}_{2}$ or $\mathrm{N}_{2} / \mathrm{O}_{2}$ gas mixture at $100 \%$ and $30 \% \mathrm{RH}$ is through the porous media. For $\mathrm{p}\left(\mathrm{O}_{2}\right) \leq 20 \%$ in $\mathrm{He} / \mathrm{O}_{2}$ or $\mathrm{N}_{2} / \mathrm{O}_{2}$ gas mixture at $100 \% \mathrm{RH}$ the main contribution to oxygen transport is through the water film surrounding a catalytic agglomerate and at $30 \% \mathrm{RH}$ the main contribution is through the ionomer surrounding the agglomerate in the CCL.

\subsection{Mass transport resistance in Cathode $100 \% \mathrm{RH}$}

The mass transport resistance $R_{W}$ in the CCL expressed in Eq. 1 relates the change in oxygen concentration during the ORR from the GDL-CCL interface at steady state to the CCL-PEM interface at the frequency domain. $R_{W}$ is a function of the steady state oxygen concentration $c_{O}^{*}$ at the CCLGDL interface. The steady state oxygen concentration can depend upon the conditions of the reactant supply to the cell and the physical properties of adjacent porous transport layers such as the GDL and microporous layer (MPL). Tab. 1 shows that CCL mass transport resistance calculated from EIS and Eq. 1 is reduced by using $\mathrm{He} / \mathrm{O}_{2}$ gas mixture, and increases with a decrease in $\mathrm{p}\left(\mathrm{O}_{2}\right)$. The diffusivity of $\mathrm{O}_{2}$ diluted in $\mathrm{N}_{2}$ at $80^{\circ} \mathrm{C}$ has been reported [8] to be $2.8 \times 10^{-5} \mathrm{~m}^{2} / \mathrm{sec}$ and the diffusion coefficient of water vapour in $\mathrm{N}_{2}$ is $3.9 \times 10^{-5} \mathrm{~m}^{2} / \mathrm{sec}$; the oxygen diffusivity in $\mathrm{He}$ is $1.13 \times 10^{-4} \mathrm{~m}^{2} / \mathrm{sec}$ and the diffusion coefficient of water vapour in $\mathrm{He}$ is $3.14 \times 10^{-4} \mathrm{~m}^{2} / \mathrm{sec}$ under the same conditions. So, when the background gas in the cathode is switched to $\mathrm{N}_{2}$ from $\mathrm{He}$, an increase in mass transport limitations can be expected. The steady state oxygen concentrations $c_{O}^{*}$ calculated from Eq. 1 are shown in Tab.1. The increase of CCL mass transport resistance $R_{W}$ when $\mathrm{O}_{2}$ is diluted with $\mathrm{N}_{2}$ is due to a decrease in the steady state oxygen concentration $c_{O}^{*}$, as shown in Tab.1. The low diffusivity of $\mathrm{O}_{2}$ diluted in $\mathrm{N}_{2}$ in the GDL can decrease the steady state oxygen concentration $c_{o}^{*}$ at the CCL-GDL interface and 
increase the mass transport resistance in the CCL. It is well known that the EIS technique can separate the charge transfer resistance from mass transport losses. This effect can be noticeable when EIS measurements in PEFCs reflect two semicircles. The one at high-medium frequencies is related to the charge transfer resistance during the ORR and decreases with increasing current density. The other one, at low frequencies, is related to oxygen transport limitations and increases with increasing current density $[3,9]$. The charge transfer resistance $R_{C}$ calculated from EIS measurements and using Eq. 1 is similar at the same $\mathrm{p}\left(\mathrm{O}_{2}\right)$ in $\mathrm{He} / \mathrm{O}_{2}$ or $\mathrm{N}_{2} / \mathrm{O}_{2}$ gas mixture. This effect can be observed in the spectra shown in Fig. 1a at frequencies from $2 \mathrm{kHz}$ to $40 \mathrm{~Hz}$. The charge transfer resistance increased with decreasing $\mathrm{p}\left(\mathrm{O}_{2}\right)$ in $\mathrm{He} / \mathrm{O}_{2}$ or $\mathrm{N}_{2} / \mathrm{O}_{2}$ gas mixture because the charge transfer during the ORR also depends on the distribution and amount of chemical species (oxygen, ions, and electrons) in the CCL electrode-electrolyte interface. Figure 1a shows that EIS spectra increase by using $\mathrm{O}_{2}$ diluted in $\mathrm{N}_{2}$ and also by reducing $\mathrm{O}_{2}$.
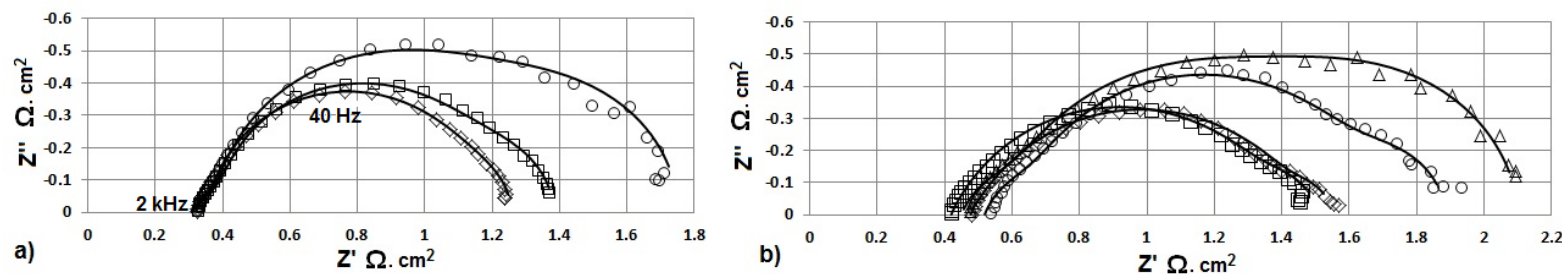

Figure 1 Comparison between experimental and simulated. Experimental $\diamond 20 \% \mathrm{O}_{2}-80 \% \mathrm{He} ; \square 20 \% \mathrm{O}_{2}-80 \% \mathrm{~N}_{2}$; ○ $10 \% \mathrm{O}_{2}-90 \% \mathrm{He} ; \Delta 10 \% \mathrm{O}_{2}-90 \% \mathrm{~N}_{2}$; - Simulated; a) Cathode $100 \% \mathrm{RH}$, b) Cathode $30 \% \mathrm{RH}$

\subsection{Mass transport resistance in Cathode $30 \% \mathrm{RH}$}

In the same way as the preceding subsection for $100 \% \mathrm{RH}$, the parameters that account for the mass transport resistance $R_{W}$ and charge transfer resistance $R_{C}$ were estimated through Eq. 1 . Figure $1 \mathrm{~b}$ shows the comparison between the simulated spectra from Eq.1 and the measured data at $30 \% \mathrm{RH}$. At $30 \% \mathrm{RH}$ the mass transport resistance in the CCL is less than that accounting for the $100 \% \mathrm{RH}$ case as shown in Tab. 1. This can be attributed to the low water content in the GDL which increases the steady state oxygen concentration $c_{O}^{*}$ in the CCL-GDL interface, as shown in Tab.1. The charge transfer resistance $R_{C}$ is higher at $30 \% \mathrm{RH}$ than for the $100 \% \mathrm{RH}$ case. Similar results were reported by Xu et al. [10]; the authors carried out EIS measurements at different cathode RH (20, 35, 50, and 
72\%) in a $5 \mathrm{~cm}^{2}$ PEFC. The CCL comprises Pt/C/ionomer agglomerates. Each agglomerate is considered to be surrounded by a film of water. At high $\mathrm{RH}$ the water film that surrounds the agglomerate increases and consequently improves catalyst utilisation in the CCL. This argument is supported by the superscript $P$ from Eq. 1 and shown in Tab. 1 . When $P=1$, a pure capacitive effect is present in the CCL [11] and therefore there is a homogeneous charge distribution between the electrode-electrolyte interface. At $100 \%$ RH there is an increase in $P$ when compared with the 30\% $\mathrm{RH}$ condition. A homogenous charge distribution between dissimilar materials improves the charge transfer during the ORR reaction.

\begin{tabular}{cccccccccc}
\hline $\begin{array}{c}\text { Cathode } 100 \% \\
\mathrm{RH}\end{array}$ & $\begin{array}{c}\mathrm{R}_{\mathrm{C}} \\
\Omega . \mathrm{cm}^{2}\end{array}$ & $\mathrm{P}$ & $\begin{array}{c}\mathrm{R}_{\mathrm{W}} \\
\Omega . \mathrm{cm}^{2}\end{array}$ & $\begin{array}{c}C_{O}^{*} \\
\mathrm{~mol} / \mathrm{cm}^{3}\end{array}$ & $\begin{array}{c}\text { Cathode 30\% } \\
\mathrm{RH}\end{array}$ & $\begin{array}{c}\mathrm{R}_{\mathrm{C}} \\
\Omega . \mathrm{cm}^{2}\end{array}$ & $\begin{array}{c}\mathrm{P} \\
\mathrm{R}_{\mathrm{W}} \\
\Omega . \mathrm{cm}^{2}\end{array}$ & $\begin{array}{c}C_{O}^{*} \\
\mathrm{~mol} / \mathrm{cm}^{3}\end{array}$ \\
\hline $20 \% \mathrm{O}_{2}-80 \% \mathrm{He}$ & 0.7944 & 0.9444 & 0.1018 & $1.549 \times 10^{-5}$ & $20 \% \mathrm{O}_{2}-80 \% \mathrm{He}$ & 0.9571 & 0.7546 & 0.0982 & $2.810 \times 10^{-5}$ \\
\hline $20 \% \mathrm{O} 2-80 \% \mathrm{~N}_{2}$ & 0.7944 & 0.9693 & 0.1963 & $8.033 \times 10^{-6}$ & $20 \% \mathrm{O}-80 \% \mathrm{~N}_{2}$ & 0.9571 & 0.7669 & 0.1227 & $2.249 \times 10^{-5}$ \\
\hline $10 \% \mathrm{O}_{2}-90 \% \mathrm{He}$ & 0.9518 & 0.9632 & 0.4172 & $3.779 \times 10^{-6}$ & $10 \% \mathrm{O}_{2}-90 \% \mathrm{He}$ & 0.9815 & 0.8896 & 0.2454 & $1.343 \times 10^{-5}$ \\
\hline $10 \% \mathrm{O}_{2}-90 \% \mathrm{~N}_{2}$ & 0.9518 & 0.9528 & 1.2025 & $1.311 \times 10^{-6}$ & $10 \% \mathrm{O}_{2}-90 \% \mathrm{~N}_{2}$ & 0.9815 & 0.8896 & 0.5153 & $5.355 \times 10^{-6}$ \\
\hline
\end{tabular}

Table 1 Parameters estimated using Eq. 1 and EIS measurements

\section{Conclusions}

This study demonstrates that it is possible to attain a deeper understanding of the internal phenomenological processes in the PEFC by coupling the experimental EIS technique with the fundamental electrochemical theory. Experimental tests were carried out on a $6 \mathrm{~cm}^{2}$ single cell operated at $80^{\circ} \mathrm{C}$ and $\mathrm{RH}$ of $100 \%$ for anode and $\mathrm{RH}$ of $100 / 30 \%$ for cathode. Different partial pressure of oxygen in $\mathrm{He} / \mathrm{O}_{2}$ and $\mathrm{N}_{2} / \mathrm{O}_{2}$ gas mixture was considered as background gases. A mathematical model predicting the CCL impedance response, derived in the authors' previous study, was applied to EIS measurements to quantify the mass transport resistance of the CCL. The results showed that it is possible to separate the CCL mass transport resistance and charge transfer resistance in EIS measurements when a PEFC is operated with low oxygen partial pressure $p\left(\mathrm{O}_{2}\right) \leq 20 \%$ in either $\mathrm{He} / \mathrm{O}_{2}$ or $\mathrm{N}_{2} / \mathrm{O}_{2}$ gas mixture. The results also showed that the low diffusivity of $\mathrm{O}_{2}$ diluted in $\mathrm{N}_{2}$ in the GDL can decrease the steady state oxygen concentration $c_{o}^{*}$ at the CCL-GDL interface and 
increase CCL mass transport resistance. This study can be applied when studying the effect of different GDL structures on equilibrium oxygen concentration at GDL-GDL interface. A further study has to be conducted to examine the effect of oxygen transportation in every single phase of the CCL on EIS measurements. This is the aim of a future work.

\section{Acknowledgements}

The provision of the data used in this work by Johnson Matthey Fuel Cells is gratefully acknowledged. The authors also acknowledge Miss. Kathleen McLoughlin for helping with the English Language.

\section{References}

[1] D. Malevich, E. Halliop, B. A. Peppley, J. G. Pharoah, K. Karan, J. Electrochem. Soc. 156 (2009) B216B224.

[2] S. Cruz-Manzo and R. Chen, J. Electroanal. Chem, 694 (2013) 45-55.

[3] S. Cruz-Manzo, R. Chen and P. Rama, Int. J. Hydrogen Energy 38 (2013) 1702-1713

[4] S. Cruz-Manzo, R. Chen and P. Rama, J. Fuel Cell Science Technology, 9 (2012) 051002

[5] T. E. Springer, T.A. Zawodzinski, M.S. Wilson, S Gottesfeld, J. Electrochem. Soc. 143 (1996) 587-599.

[6] N. Wagner, and E. Gülzow, J. Power Sources, 127, (2004) 341-347

[7] J. Zhang, PEM Fuel Cell Electrocatalysts and Catalysts Layers, Springer, London, 2008.

[8] Fu S. Richard, Zhang Xiaoyu, Pasaogullari Ugur, ECS trans., 25 (1), 323 (2009).

[9] Paganin VA, Oliveira CLF, Ticianelli EA, Springer TE, and Gonzalez ER. Electrochimica Acta. 43 (1998) 3761-3766.

[10] H. Xu, Y. Song, H. R. Kunz, and J. M. Fenton, J. Electrochem. Soc. 152 (2005) A1828-A1836.

[11] C. H. Hsu and F. Mansfeld, Corrosion, 57, (2001) 747-748. 